\title{
Suggestions for Solutions to the Problems of Interrupting, Speaking at the Same Time, Inability to be Pleasant-Spoken and Debonair within the Context of Action Research in Education
}

\author{
Orhan Bozdemir \\ Atatürk University, Kazım Karabekir Faculty of Education, Department of German Language Education, \\ Turkey. \\ Email:bozdemir@atauni.edu.tr
}

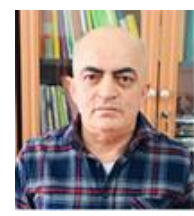

\begin{abstract}
This qualitative study is based on the solutions offered by the students of the "Action Research in Education" course within the scope of the pedagogical formation certificate program at Atatürk University Faculty of Education during a 10-minute presentation in the activity called "one solution to one problem." The data collected from the presentations were subjected to content analysis, and sentences were selected as the unit of analysis and tabulated. Subsequently, with the application of a scale developed by the researcher to the same students, two problems, which were not studied sufficiently during the presentations and that the researcher and students agreed were highly critical, were identified. An open-ended scale was applied to the same students about the problems of interruption/overlap and being unfriendly / speaking rudely, and the solution proposals developed by prospective teachers were analyzed by using the descriptive data analysis technique. It was determined that the prospective teachers had a certain awareness of these problems and could produce solutions that can be adapted to the education system. We believe that the study is also important in that it reflects the perspectives of prospective teachers who are important stakeholders of education.
\end{abstract}

Keywords: Action research in education, Interruption-overlap, Being unfriendly-speaking rudely, Prospective teachers, Quantitative screening model.

Citation | Orhan Bozdemir (2020). Suggestions for Solutions to the Problems of Interrupting, Speaking at the Same Time, Inability to be Pleasant-Spoken and Debonair within the Context of Action Research in Education. Asian Journal of Education and Training, 6(2): 130-135.

History:
Received: 2 December 2019

Revised: 7 January 2020

Accepted: 10 February 2020

Published: 18 March 2020

Licensed: This work is licensed under a Creative Commons

Attribution 3.0 License (cc)

Publisher: Asian Online Journal Publishing Group
Funding: This study received no specific financial support

Competing Interests: The author declares that there are no conflicts of interests regarding the publication of this paper.

Transparency: The author confirms that the manuscript is an honest, accurate, and transparent account of the study was reported; that no vital features of the study have been omitted; and that any discrepancies from the features of the study have been omitted
study as planned have been explained.

Ethical: This study follows all ethical practices during writing.

\section{Contents}

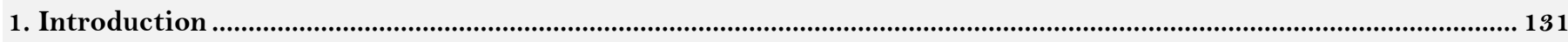

2. Method

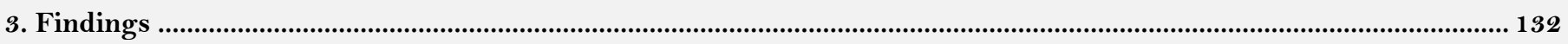

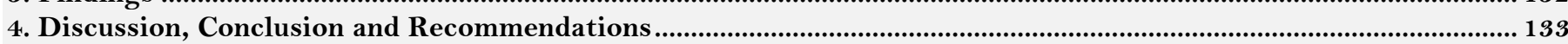

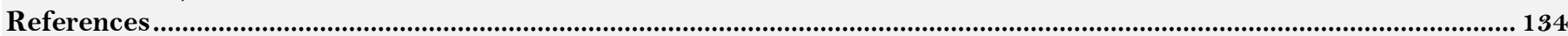




\section{Contribution of this paper to the literature}

It is a study that evaluates problems such as Interrupting, speaking at the same time, inability to being pleasant-spoken and debonair in in educational activity from the perspective of prospective teachers. It is thought that it may contribute to the literature in terms of possible solutions for the issue.

\section{Introduction}

In Turkey, various models have been applied in teacher education in the historical process. With a decision taken by the Council of Higher Education in the academic year of 2009-2010, Non-Thesis Master's Programs which had been launched to train teachers for secondary schools were closed, and the teacher needs of these schools were met with the Pedagogical Formation Certificate Program (AzAr, 2011). Nowadays, the pedagogical formation certificate program provides the opportunity to become a teacher for students who have been educated or are being educated at academic units other than faculties of education (Demirtas \& Kirbac, 2016). Pedagogical formation is the educational formation that must be acquired to be able to teach at a school. For this formation, prospective teachers take various courses and practice teaching at schools (Uzuner, 2005).

One of the courses provided in the pedagogical formation certificate program is the "Action Research in Education" course. Although action research in education is based on the work of John Dewey, after the Second World War, Stephen Corey, a professor at Colombia University, pioneered action research and was the first to systematically apply this research method to solving educational problems (Aksoy, 2003). The most important purpose of action research in education is to systematically understand the realities that emerge in the world of education and thus try to change and improve education (Kuzu, 2009).

According to some classifications, one of the applied qualitative research methods, action research is a preplanned, organized and cooperative systematic review to improve the quality of life through critical reflection and questioning (Bogdan \& Biklen, 1998; Mills, 2000; Uzuner, 2005). In this research approach, which is based on the critical theory, the aim is not only to understand the meanings and behaviors of the individuals studied, but also to change them (Ekiz, 2003). People share their thoughts and knowledge on a studied subject and offer their solutions to the problems that are examined. This way, new action plans are designed to achieve the objectives of the research (Mills, 2000). Action research is solution-oriented research conducted by a group: a group of people identifies a problem, does something to solve it, sees how successful their efforts are and tries again if they are not satisfied with the outcome; in short, they learn by doing in action research (Beverly, 1993).

"Interruption/interrupting others" is defined as interrupting someone while they are speaking (Schegloff, 2001). The attempt of interruption is successful when the person, who is interrupted, stops speaking. In a successful interruption, the person who interrupts the other person controls the conversation and therefore executes their power. Overlap is, on the other hand, simultaneous talk by two or more participants of a conversation and is also considered an attempt to establish control and power by the person who overlaps with the person speaking (Huls, 2000).

In conversations, there is a turn-taking organization where participants speak one at a time in alternating turns, which allows the participants to organize and tailor the interaction. The turn-taking organization is the basic organization of a social relationship established in a conversation-based interaction environment (Sacks, Schegloff, \& Jefferson, 1974). In this sense, the attempt to interrupt is also defined as interrupting a speaker who has the right to speak in a conversation (Yurtdaş, Atakan, \& Tezerişir, 2011).

If two people speak at the same time, it means that the speakers are not listening to each other, which is unacceptable according to the cultural values most societies. Indeed, it is not a coincidence that Mawlana's Masnavi opens with the word "bişnev," which means "listen". Because to speak, one has to listen first. "Start speaking by giving ear" says Mawlana.

When it comes to good words or speaking politely, the Holy Quran compares beautiful words to a tree with pleasant fruits (İbrâhim, 14/24-26) and emphasizes that the word must be true (An-Nisa, 4/9; Al-Ahzâb, 33/7071), beautiful (Al-Baqarah, 83; 4/An-Nisa, 4), soft and gentle (Taha, 20/44; Al-Isra, 17/28). Regardless of the form of the conversation, a smiling face and sweet tongue are always very important. "And tell My servants to say that which is best" (Al-Isra,17/53). In addition to "...and speak to people good [words]" (Al-Baqarah 2/83), the hadith "A good word is charity" (al-Bukhārī- Edeb, p.34) (Kavaklığlu, 2010) draws our attention to the importance of good words (Seker, 2011).

A lot of research has been conducted in Turkey about classroom management, which is very important for maintaining the order of the classroom and the quality of teaching. Although these studies have offered various solutions to the problems that may be encountered in the classroom, there is no detailed study on the importance of being unfriendly/speaking rudely in the classroom. In this context, it is thought that examining these problems within the framework of the "Action Research in Education" course will not only provide solution-oriented approaches to the subject but also help us see what prospective teachers think about these problems. In this study, on the subjects of "interruption/overlap" and "being unfriendly/speaking rudely", we tried to learn the views of 75 students, all of whom were philology graduates who took the "Action Research in Education" course within the framework of a pedagogical formation certificate program offered at Atatürk University Faculty of Education. By doing so, we aimed to determine how aware the prospective teachers were about the topic and collect their solution proposals to the problems.

\subsection{Objective}

In this study, on the topics of "interruption/overlap" and "being unfriendly/speaking rudely", we tried to learn the views of 75 students, all of whom were philology graduates who took the "Action Research in Education" course within the framework of a pedagogical formation certificate program offered at Atatürk University Faculty of Education. By doing so, we aimed to determine how aware the prospective teachers were about the topic and collect their solution proposals to the problems. 


\section{Method}

\subsection{Research Model}

This study is a mixed-method study in which elements of qualitative and quantitative research approaches are combined. In mixed-methods, qualitative and quantitative research approaches are utilized together at the stages of data collection and analysis to characterize the problems that are the subject of the research and determine the solutions (Leech \& Onwuegbuzie, 2009). The design of the study was determined as sequential transformative design in order to "emphasize the dominant paradigm" (Tunalı, Gözü, \& Ozen, 2016). In this context, by using the most dominant findings among the findings obtained with the qualitative research model, a quantitative screening model was developed.

For an activity named "One solution to one problem" in the "Action Research in Education" course, the students were asked to prepare 10-minute presentations about a problem related to education and present their solution proposals to the problems. Subsequently, with the application of a scale developed by the researcher to the same students, two problems, which were not studied sufficiently during the presentations and that the researcher and students agreed were highly critical, were identified. These two problems were identified as "interruption/overlap" and "being unfriendly/speaking rudely." Then, an open-ended scale was applied to the same students about these problems, and their solution proposals were analyzed with the descriptive data analysis technique. The data collected from the presentations were subjected to content analysis, and sentences were selected as the unit of analysis and tabulated. The participants were asked to select the solution proposal which they deemed the most appropriate.

\subsection{Sample}

The study enrolled 75 students who took the "Action Research in Education" course within the framework of the pedagogical formation certificate program offered at Atatürk University Faculty of Education in the academic year of 2018-2019. Of the students who were all educated at the philology departments of various faculties of letters, 12 were German Language and Literature graduates, 24 were Arabic Language and Literature graduates, 35 were English Language and Literature graduates, and 4 were Russian Language and Literature graduates.

\subsection{Data Collection Tool}

An independent data collection tool compiled from the participants' views on the topic was used. The survey contained six items about the causes of the problems of interruption/overlap and being unfriendly/speaking rudely, about solution proposals to the problems and about what kind of reactions need to be given to raise awareness in students about these problems.

\subsection{Data Analysis}

The data that were obtained are expressed as a percentage (\%) and frequency (f). Considering that the sample consisted of 75 prospective teachers who graduated from philology departments, and the results may be generalized only to a certain extent, the results that the participants deemed prominent were compared to the results obtained from similar studies in the literature.

\section{Findings}

The percentage and frequency distributions of the answers of the pre-service philology graduate teachers to the questionnaire which was compiled from their own opinions about the problems of "interruption/overlap" and "being unfriendly/speaking rudely" are detailed in the tables below.

\begin{tabular}{l|c|c} 
Table-1. Percentage and frequency values of the participants' preferences about the causes of the problems of interruption-overlap. & $\mathbf{f}$ & $\mathbf{\%}$ \\
\hline Possible Causes & 21 & 28.0 \\
\hline Selfishness & 30 & 40.0 \\
\hline Lack of respect for others & 11 & 14.6 \\
\hline Not knowing how to listen to others & 9 & 12.0 \\
\hline Lack of empathy & 4 & 5.3 \\
\hline Environmental factors (family, friends and immediate surroundings) & 4 \\
\hline
\end{tabular}

As seen in Table 1, the prospective teachers mostly thought that the problem of interruption-overlap is caused by a lack of respect for others. The second major cause of this problem was selfishness, according to the participants. Interestingly, very few prospective teachers attributed the cause of this problem to environmental factors.

\begin{tabular}{|c|c|c|}
\hline Solution Proposals & f & $\%$ \\
\hline The problem should be addressed, and children should be given responsibilities in primary schools & 14 & 18.6 \\
\hline The subject should be included in the curriculum within the framework of school etiquette & 19 & 25.3 \\
\hline There must be rules based on a punishment system in classrooms & 7 & 9.3 \\
\hline Awareness should be created about the subject through TV shows and panels & 12 & 16.0 \\
\hline Children should be provided with habits such as reading to improve their patience & 23 & 30.6 \\
\hline
\end{tabular}

In Table 2, which contains the suggestions of the prospective teachers for this problem, the idea that solutions based on a punishment system cannot be effective comes to the fore. On the other hand, the participants mostly selected "Children should be provided with habits such as reading books to improve their patience." It was remarkable that the prospective teachers were aware of the importance of patience. 
Table-3. Percentage and frequency values of the participants' preferences about the reactions that can be given to raise awareness about the problem of interruption-overlap.

\begin{tabular}{|c|c|c|}
\hline Reactions that can be given & f & $\%$ \\
\hline $\begin{array}{l}\text { Before we start talking, we can express our sensitivity on this issue and react when we are interrupted } \\
\text { by not listening to or responding to the student who has interrupted }\end{array}$ & 29 & 38.6 \\
\hline $\begin{array}{l}\text { Altogether, we can close our ears to the student interrupting and encourage other students to do so } \\
\text { when they are interrupted }\end{array}$ & 11 & 14.6 \\
\hline Together, we can stare at the floor when a student has interrupted & 9 & 12.0 \\
\hline We can talk altogether at the same time when a student has interrupted & 12 & 16.0 \\
\hline We can leave the classroom when a student has interrupted & 14 & 18.6 \\
\hline
\end{tabular}

As seen in Table 3, the most preferred reaction was "Before we start talking, we can express our sensitivity on this issue and react when we are interrupted by not listening to responding to the student who has interrupted." It may also be inferred from the table that "closing our ears to the student interrupting and encouraging other students to do so when they are interrupted," "staring at the floor when a student has interrupted" and "talking altogether when a student has interrupted" reactions were preferred by almost half of the participants. Moreover, only $14 \%$ of the participants preferred the reaction of "leaving the classroom when a student has interrupted," which is a harsher reaction.

\begin{tabular}{l|c|c} 
Table-4. Percentage and frequency values of the participants' preferences about the causes of being unfriendly-speaking rudely. \\
\hline Possible Causes & f & $\%$ \\
\hline The inability to learn to cope with problems & 32 & 42.6 \\
\hline Lack of self-esteem and self-love & 13 & 17.3 \\
\hline Negative effects of technology & 22 & 29.3 \\
\hline Environmental factors (family, friends and immediate surroundings) & 8 & 10.6 \\
\hline
\end{tabular}

According to the participants, the main cause of the problem of being unfriendly-speaking rudely was the inability to learn to cope with problems. As the second and third causes, they saw the negative effects of technology and lack of self-esteem and self-love, respectively. According to the participants, environmental factors were the least probable cause of this problem.

Table-5. Percentage and frequency values of the participants' preferences about possible solutions to the problem of being unfriendlyspeaking rudely.

\begin{tabular}{|c|c|c|}
\hline Possible solution proposals & f & $\%$ \\
\hline $\begin{array}{l}\text { The problem should be addressed within the family and primary school, and individuals should be } \\
\text { carefully monitored }\end{array}$ & 42 & 56 \\
\hline Students should maintain distance from social media & 8 & 11 \\
\hline The concept of tolerance should be emphasized & 6 & 8 \\
\hline It should often be emphasized that smiling is a gift of love & 4 & 5 \\
\hline $\begin{array}{l}\text { It should be emphasized that saying hello means "I mean no harm to you", and the act of greeting is } \\
\text { the best way to convey our respect, love, care and kindness to the other person and is a necessity of } \\
\text { being human }\end{array}$ & 3 & 4 \\
\hline $\begin{array}{l}\text { We should constantly remind our students how much smiling and friendly conversations feed the } \\
\text { human soul and how important they are in relationships }\end{array}$ & 12 & 16 \\
\hline
\end{tabular}

As seen in Table 5, the most probable solution to the problem of being unfriendly-speaking rudely was to "address the problem within the family and primary school and monitor individuals." The second most preferred solution proposal was "We should constantly remind our students how much smiling and friendly conversations feed the human soul and how important they are in relationships." These were followed by the following solution proposals respectively: "Students should maintain distance from social media," "The concept of tolerance should be emphasized," "It should often be emphasized that smiling is a gift of love," and "It should be emphasized that saying hello means 'I mean no harm to you,' and the act of greeting is the best way to convey our respect, love, care and kindness to the other person and is a necessity of being human."

Table-6. Percentage and frequency values of the participants' preferences about the reactions that can be given to raise awareness on the problem of being unfriendly-speaking rudely.

\begin{tabular}{|c|c|c|}
\hline Reactions that can be given & f & $\%$ \\
\hline We can solve the problem by being a role model for students, not by warning them & 28 & 45.3 \\
\hline We may choose not to respond to students' requests that they express in a scowling manner. & 8 & 10.6 \\
\hline $\begin{array}{l}\text { We can give examples about the importance of smiling (e.g., Why do we smile when someone is taking a } \\
\text { photo of us?) }\end{array}$ & 20 & 26.6 \\
\hline We can often ask students what kind of a society they want to live in & 9 & 12 \\
\hline $\begin{array}{l}\text { By using the themes of 'Mirror' and 'Smiling eyes', we can tell our students 'change yourself so that the } \\
\text { world changes' }\end{array}$ & 4 & 5.3 \\
\hline
\end{tabular}

It may be inferred from Table 6 that the most preferred reaction that could be given to the problem of being unfriendly-speaking rudely was "We can solve the problem by being a role model for students, not by warning them," which is a 'teacherly' attitude, followed by "We can give examples about the importance of smiling (e.g., Why do we smile when someone is taking a photo of us?)" which is also a method applied frequently by teachers.

\section{Discussion, Conclusion and Recommendations}

We believe that a tremendous amount of responsibility is on the shoulders of us, educators, to overcome the problems of "interruption-overlap" and "being unfriendly- speaking rudely," which are never compatible with our 
cultural values but which, unfortunately, have become quite common to the extent that these behaviors are accepted to be normal. It is possible to give thousands of beautiful examples from Turkish history or literature with regard to these problems. However, today's social life is unfortunately so far from these good examples. Furthermore, as in many other issues, the solution lies in education.

In this study conducted with 75 prospective teachers who took the "Action Research in Education" course within the scope of a pedagogical formation certificate program, first of all, we refreshed our knowledge about the pedagogical formation certificate program and the "Action Research in Education" course with citations from prominent studies. Subsequently, we analyzed the results of the "One solution to one problem" activity we carried out with our students in this course, and we identified two problems. By using a scale that we developed, we collected the prospective teachers' proposals of solutions to these two problems.

The first of the two problems was "interruption-overlap," which is highly common in Turkish society and about which especially class teachers need to warn their students in almost every lesson. According to the participants, the most probable causes of this problem were selfishness, lack of respect for others and not knowing how to listen to others. Their solution proposals to this problem were "teaching students how to listen to others," "addressing the problem in primary schools," "establishing rules in the classroom," "ensuring that children take responsibility in this regard," "including the subject in the curriculum within the framework of school etiquette" and "creating awareness about the subject through TV shows especially for children and panels." When the prospective teachers were asked to re-evaluate the most prominent solution offers, it was seen that they mostly thought that a solution based on a punishment system would not be effective (Table 2). On the other hand, most of them were of the idea that improving children's patience through habits like reading would be more effective.

Moreover, the participants gave the following responses to the question of how they could create awareness on this problem, and what kind of reactions they could give: "Before we start talking, we can express our sensitivity on this issue and react when we are interrupted by not listening to or responding to the student who has interrupted," "Altogether, we can close our ears to the student interrupting and encourage other students to do so when they are interrupted," "Altogether, we can stare at the floor, talk at the same time, or leave the classroom when a student has interrupted."

The second problem for which we sought solutions from the point of view of the prospective teachers and which is very important for our social peace was the problem of being unfriendly-speaking rudely. The probable causes of this problem, according to our participants, were the inability to learn to cope with problems, lack of selfesteem and self-love and negative effects of technology.

As solution proposals, the participants stated that "The problem should be addressed within the family and primary school," "Students should maintain distance from social media," and "The concept of tolerance should be emphasized." They also underlined that it should be emphasized by teachers and parents that "smiling is a gift of love" and "how friendly conversations feed the human soul, and how important they are in relationships." Additionally, the participants stated that "It should be emphasized that saying hello means 'I mean no harm to you', and the act of greeting is the best way to convey our respect, love care, and kindness to the other person and is a necessity of being human."

Finally, to the question of how they could raise awareness in students about this problem and what kind of reactions they should give to the students, they stated that they should think in a solution-oriented manner, not in a problem-oriented manner, and they could solve problems by being a role model for students, not by warning them. They also said that teachers should be friendly and in search of happiness in every situation and reflect this to their students. Additionally, they stated that they may choose not to respond to students' requests that they express in a scowling manner, and they must teach their students to be unconditionally friendly towards others and speak politely with them. Finally, they stated that they could provide examples about the importance of smiling by asking questions such as 'Why do we smile when someone is taking a photo of us?' or 'Why do we delete our photos where we pout?', and by using the themes of 'Mirror' and 'Smiling eyes', they can tell their students 'change yourself so that the world changes.'

We hope that our study will be a step towards taking into account the views of prospective teachers who are young stakeholders of education.

\section{References}

Aksoy, N. (2003). Action research: A method to be used to improve and change educational practices. Educational Administration: Theory and Practice, 36(36), 474-489.

AzAr, A. (2011). A discourse on teacher education in Turkey: Qualifications, is quantity. Journal of Higher Education and Science, 1(1), 36-38. Beverly, J. (1993). Teacher-as-researcher. ERIC digest. Retrieved from http://www.ericdigests.org/1993/researcher.htm.

Bogdan, R. C., \& Biklen, S. K. (1998). Qualitative research for education: An introduction to theories and methods (5th ed.). Boston, MA: Pearson A $\&$ B.

Demirtas, H., \& Kirbac, M. (2016). Pedagogical formation certificate program students' views on pedagogical formation education. Trakya University Faculty of Education Journal, 6(2), 138-152.

Ekiz, D. (2003). Introduction to research methods and applications in education: Qualitative, quantitative and critical theory methodologies. Ankara, Turkey: Anı Publishing Company.

Huls, E. (2000). Power in Turkish migrant families. Discourse \& Society, 11(3), $345-372 . \quad$ Available at: https://doi.org/10.1177/0957926500011003004.

Kavaklı̆̆lu, M. (2010). The prophed against some unkind words and behaviors Hitit University. Journal of Theology Faculty, 9(18), 25-60.

Kuzu, A. (2009). Action research in teacher training and professional development. Journal of International Social Research, 2(6), 425-433.

Leech, N. L., \& Onwuegbuzie, A. J. (2009). A typology of mixed methods research designs. Quality \& Quantity, 43(2), 265-275. Available at: https://doi.org/10.1007/s1 1135-007-9105-3.

Mills, G. E. (2000). Action research: A guide for the teacher researcher. One Lake Street, Upper Saddle River, New Jersey 07458: Prentice-Hall, Inc.

Sacks, H., Schegloff, E. A., \& Jefferson, G. (1974). A simplest systematics for the organization of turn taking for conversation. Language, 50(4), 696-735. Available at: https://doi.org/10.2307/412243.

Schegloff, E. A. (2001). Accounts of conduct in interaction: Interruption, overlap, and turn-taking. In Handbook of sociological theory (pp. 287-321). Boston, MA: Springer.

Seker, N. (2011). Nebevî method in oral communication. Journal of Community Sciences, 5(10), 111-128. 
Tunal, B., Gözü, O., \& Ozen, G. (2016). Using qualitative and quantitative research methods together mixed research method. Anadolu University, Faculty of Communication, International Refereed Journal, 24(2), 106-112.

Uzuner, Y. (2005). Action research with examples from special education. Ankara University Faculty of Educational Sciences Special Education Journal, 6(2), 1-13.

Yurtdaş, G. T., Atakan, M., \& Tezerişir, A. (2011). The relationship between gender and speech interruption in verbal interactions. Studies in Psychology, 31(1), 105-117. 